\title{
InoBioProd: innovation challenges and scientific perspectives
}

\section{Cristina Popovici ${ }^{1}$, Vavil Caragia ${ }^{2}$, Anatoli Cartasev ${ }^{2}$, Olga Migaltiev $^{2}$, Ghenadie Coev $^{2}$, Roman Golubi ${ }^{2}$, Nina Bogdan ${ }^{2}$, Irina Grumeza ${ }^{2}$}

\author{
1 - Faculty of Food Technology, Technical University of Moldova \\ 2 - Scientific and Practical Institute of Horticulture and Food Technologies, \\ Moldova
}

Keywords:

InoBioProd

Milk

Goat

Innovation

Research

Education

Article history:

Received

30.04.2017

Received in revised

form 24.06.2017

Accepted 29.06.2017

\section{Corresponding author:}

Cristina Popovici

E-mail:

cristina.popovici@

toap.utm.md

DOI:

10.24263/2304-

974X-2017-6-2-17

\section{Abstract}

Introduction. InoBioProd represents the project under the title ,Innovative product from goat milk with high biological properties" listed as independent project for young researchers, domain „Biotechnology”, grant agreement No 16.80012.51.23A.

Materials and methods. Agrofood industrial wests and byproducts are used as a source of bioactive copounds. At the same time goat milk, indigenous lactic acid bacteria and fermented milk products with high biological properties are main objects of research. Project intends application of standard and innovative methods and processes.

Results and discussion. The scientific results, in particular the expected technologies are absolutely innovative for the Republic of Moldova and are in the framework of the UNICEF recommendations for food and nutrition policy. InoBioProd contribues to the development of investigations in the field of food biotechnology, engineering technology, food chemistry and microbiology, offering a high potential for application: innovative methods for manufacturing of bioactive compounds from local food sources; chemical composition and functional potential of the bioactive compounds; characteristics of goat milk; isolation and identification of lactic acid bacteria from dairy products of spontaneous fermentation; symbiotic indigenous cultures of lactic acid bacteria; justified scientific manufacturing processes and recipes for fermented dairy products from goat milk and scientific development of methods for evaluation of the self-life of designed fermented dairy products. Special attention of InoBioProd gives to the elaboration of $\mathrm{BSc}, \mathrm{MSc}$ and $\mathrm{PhD}$ thesis, dissemination of scientific results at national and international levels.

Conclusions. The Project was developed under the main provision of the local market - the lack of industrial production of the goat milk and products. In addition, it aims to initiate, develop and strengthen new collaborations of young scientists from $R \& D$ and higher education institutions. 


\section{Introduction}

In many regions of the world, food industry follows similar trends: increasing affluence, demographic changes and enhance consumer awareness of health. This trend has led to increased demand for ingredients and natural food products. For this reason, food industry experts are concerned on development of new, innovative products with ingredients that have additional benefits. One of the present trends of consumers is a greater consumption of foods with high content in biologically active compounds with positive effects on health.

Likewise, consumer interest has increased for „clean label” foods, with low content or without synthetic additives, but at the same time with high innocuity. InoBioProd proposes the use of indigenous agrofood sources known to have antioxidant and antimicrobial potential in order to improve food quality and durability and, therefore, food safety of fermented dairy products from goat milk. In addition, InoBioProd is aimed to strengthen scientific knowledge, promoting scientific cooperation and encouraging the interaction between the research institution and higher education and the creation of a common and shared scientific results, information and knowledge. Development of fundamental and applied studies with a high impact on the field of food technology, valorisation of local agrofood sources through innovative methods with the possibility of their use in diversification of fermented goat dairy products is an important issue of the InoBioProd.

In the Republic of Moldova is observed upward trend in the herd of goats, which currently lists about 120-130 thousand heads and produce about 70 thousand tons of milk annually. Goat milk has a promising source of protein, vitamins, minerals and fatty acids $[2,4,7]$. Goat milk has better digestibility, reduced allergenicity, due to the low content of lactose $[11,15]$. From goat milk usually obtain butter, yogurt, sour milk, catic. Fermented dairy products has delicios sensory properties, fine consistency and pleasant specific taste. In the Republic of Moldova goat milk is not used at industrial level and in the markets those dairy products from goat milk is absent. Currently Moldova has no scientific results about goat milk processing.

Internationally the theme proposed for research is carried out on the preparation and optimization of manufacturing technology of yogurt from goat milk $[3,10,20]$. There are also conducted research on the analysis of physical-chemical, microbiological and sensorial properties of yogurt from goat, bovine and cow milk [9, 13, 23]. There are comparative study on influence of the incorporation of synthetic and natural preservatives on the yogurt characteristics [6]. Some researchers conducted studies regarding the improvement of the properties of goat milk yogurt by adding aromatic oils and plant [1]. The study conducted by scientists from Bulgaria showed the possibility of yougurt supplimentation with fruit juice [5]. Documented results are aimed to understand the correlation between fortification with shell pineapple and physico-chemical and rheological properties of yogurt with probiotics [21]. The results of researchers from Sri Lanka have shown that incorporation of beetroot juice can be an insight to improve the characteristic organoleptic properties of goat milk [8]. A group of scientists studied the effect of Cinnamomum verum yogurt fortification with Allium sativum and the bifidobacteria [24]. The level of applied knowledge about technology production of yogurt from goat milk and nutritional properties in our country is lower compared to other developed countries.

The research team has already achieved certain results in the field (scientific results have been disseminated in research journals and communicated at different scientific events) [16-19]. Scientific and research activities planned under the Project InoBioProd is strictly necessary to extend these achievements and obtain some of innovative elements of research. 


\section{Mission of the InoBioProd}

Integration of the Republic of Moldova into the European Union imposes special requirements on the quality of food products in the country. Increased worldwide demand for goat milk production due to impressive health benefits [22, 25]. Ministry of Agriculture and Food Industry of the Rpublic of Moldova also notes the need of manufacturing of these products on industrial scale, and lack of advanced technologies, normative documents regarding the quality and safety of those products in accordance with international regulations.

InoBioProd Project provides the development and further research with impact in valorisation of goat milk through innovative methods $[12,16]$. In particular, it is planned to develop and diversify fermented dairy products with indigenous lactic acid bacteria with characteristic symbiotic and bioactive compounds with functional potential (Table 1).

InoBioProd research Project solves scientifical and practical problems. Project research team includes young competent specialists in organizing and conducting investigation. A strong innovation potential resulting from large-scale approach to technology development of fermented dairy products with high biological properties, due to the direct colaboration of specialists in food technology, biotechnology and microbiology.

\section{Potential Activities of InoBioProd}

The Project facilitate the development of science in the field, ensure increasing of research capabilities, innovation and dissemination of obtained scientific results and strengthening scientific collaboration of young researchers from R\&D and higher education institutions.

Reseachers use obtained bioactive compounds from local agrofood sources in the manufacture of fermented dairy products from goat milk with indigenous lactic acid bacteria. The InoBioProd potential activities are organized in 4 Work Packagies, each managed by a work package leader responsible for the outcome and timing of its work package (Figure 1).

The figure 1 shows the graphical presentation of the four WPs and their independencies. WPs include also the main outputs, which will be obtained thanks to the planned activitiess. Relationship with Scientific and Practical Institute of Horticulture and Food Technologies (SPIHFT) and Technical University (TUM) are also highlighted.

\section{Methods and experimental protocols}

The research is organized into special teams according to the activity directions. The Project is designed with technological, physico-chemical, biochemical and microbiological standard methods, in accordance with the ISO (Official Methods of Analysis of AOAC International). Statistical method, including the analysis of experimental data by means of control charts X-R, $\mathrm{S}^{2}$, and other methods are applied. The Project applies new methods and processes (Figure 2). 
Strategies of the InoBioProd Project

\begin{tabular}{|c|c|}
\hline Concept & $\begin{array}{l}\text { - The Project is oriented for production (from laboratory to } \\
\text { market). } \\
\text { - Elaboration of methods, technologies and technical regulations } \\
\text { for fermented dairy products from goat milk. } \\
\text { - Project includes strategic direction of development of } \\
\text { innovative and competitive food product with positive } \\
\text { implications on consumer health. }\end{array}$ \\
\hline Objects & $\begin{array}{ll} & \text { Bioactive compounds from local food sources. } \\
- & \text { Goat milk. } \\
- & \text { Indigenous lactic acid bacteria. } \\
- & \text { Fermented dairy products with high biological properties. }\end{array}$ \\
\hline Objectives & 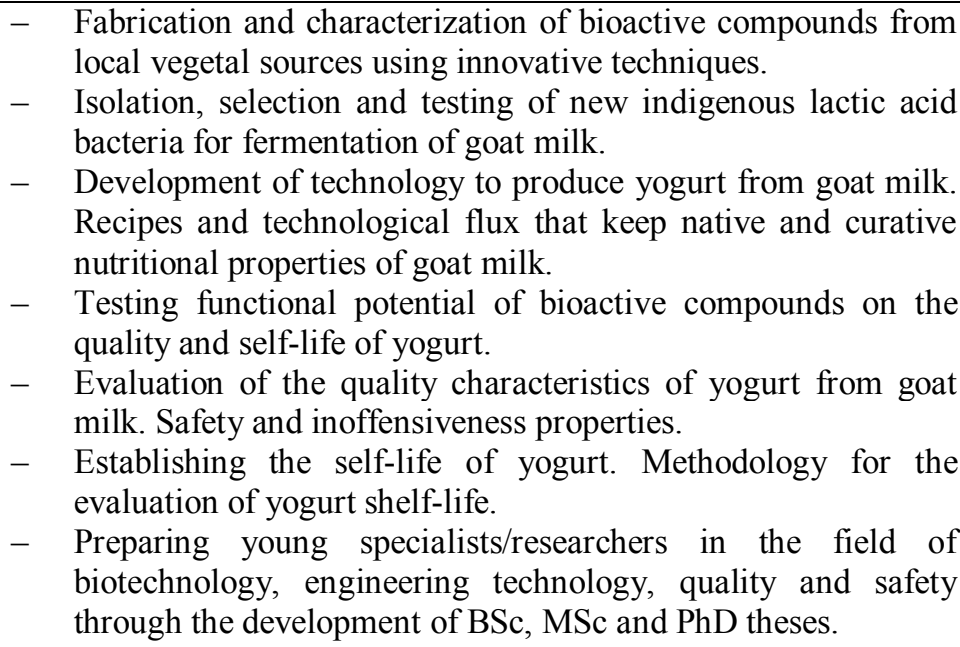 \\
\hline $\begin{array}{l}\text { Ideas and } \\
\text { original features }\end{array}$ & $\begin{array}{l}\text { - } \text { Advanced Processing of local food sources to obtain bioactive } \\
\text { compounds with functional potential. } \\
\text { - Use of lactic acid bacteria with symbiotic characteristics from } \\
\text { indigenous sources. } \\
\text { - Creation of fermented dairy products from goat milk with high } \\
\text { biological properties for consumers benefits. }\end{array}$ \\
\hline $\begin{array}{l}\text { Interdisciplinary } \\
\text { character }\end{array}$ & $\begin{array}{l}\text { - Novelty and unique methodological approach of the Project } \\
\text { consists in different fields of application (biotechnology, } \\
\text { engineering technology, chemistry, microbiology) to obtain } \\
\text { original data for the creation of innovative product. } \\
\text { - Project team consists from young researchers of different } \\
\text { profiles that will ensure a comprehensive approach in goals } \\
\text { achievement. } \\
\text { The Project intends collaboration of young and experiensed } \\
\text { researchers in the field of food industry. }\end{array}$ \\
\hline
\end{tabular}




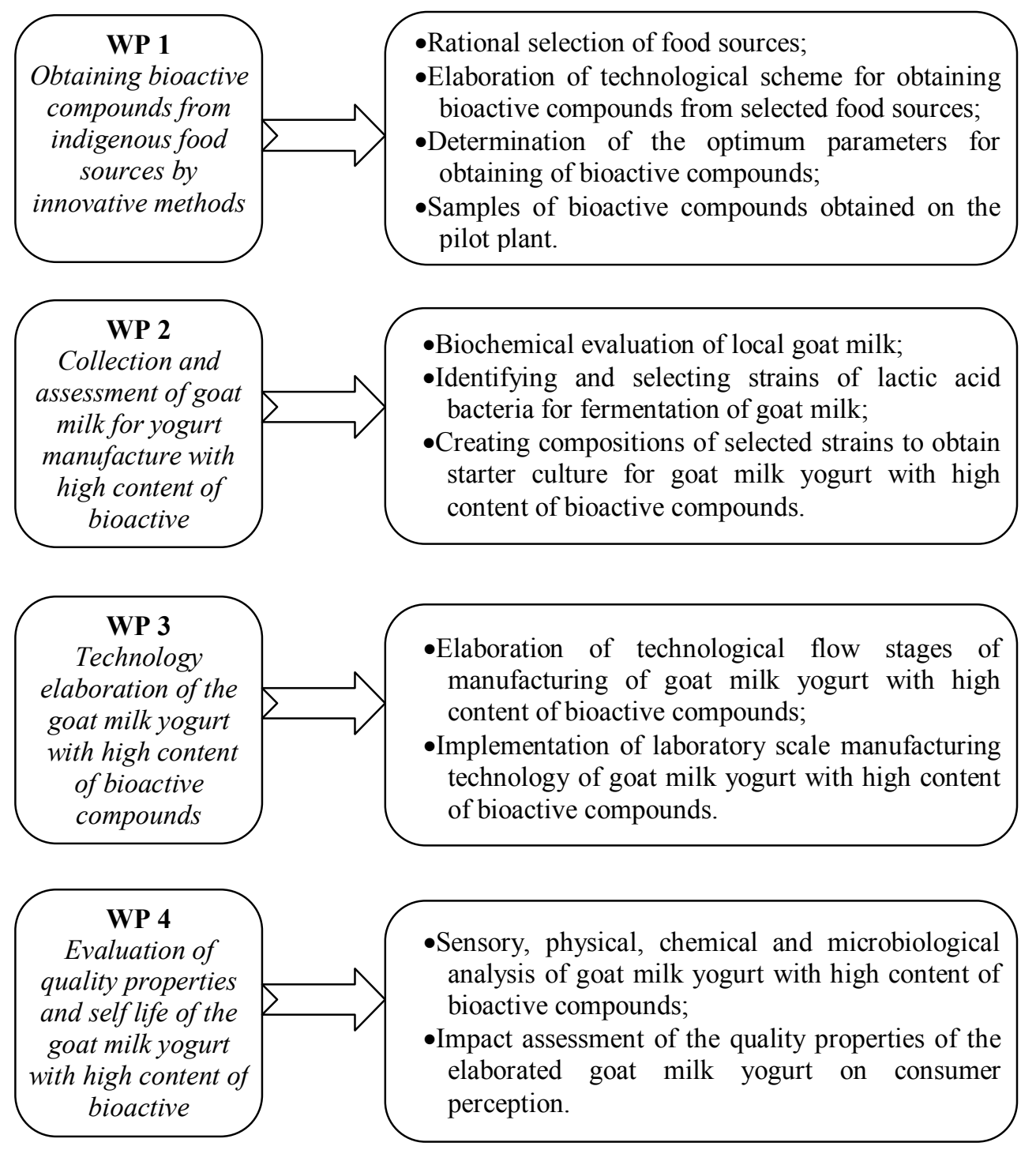

Figure 1. Main stages of realization of the InoBioProd 


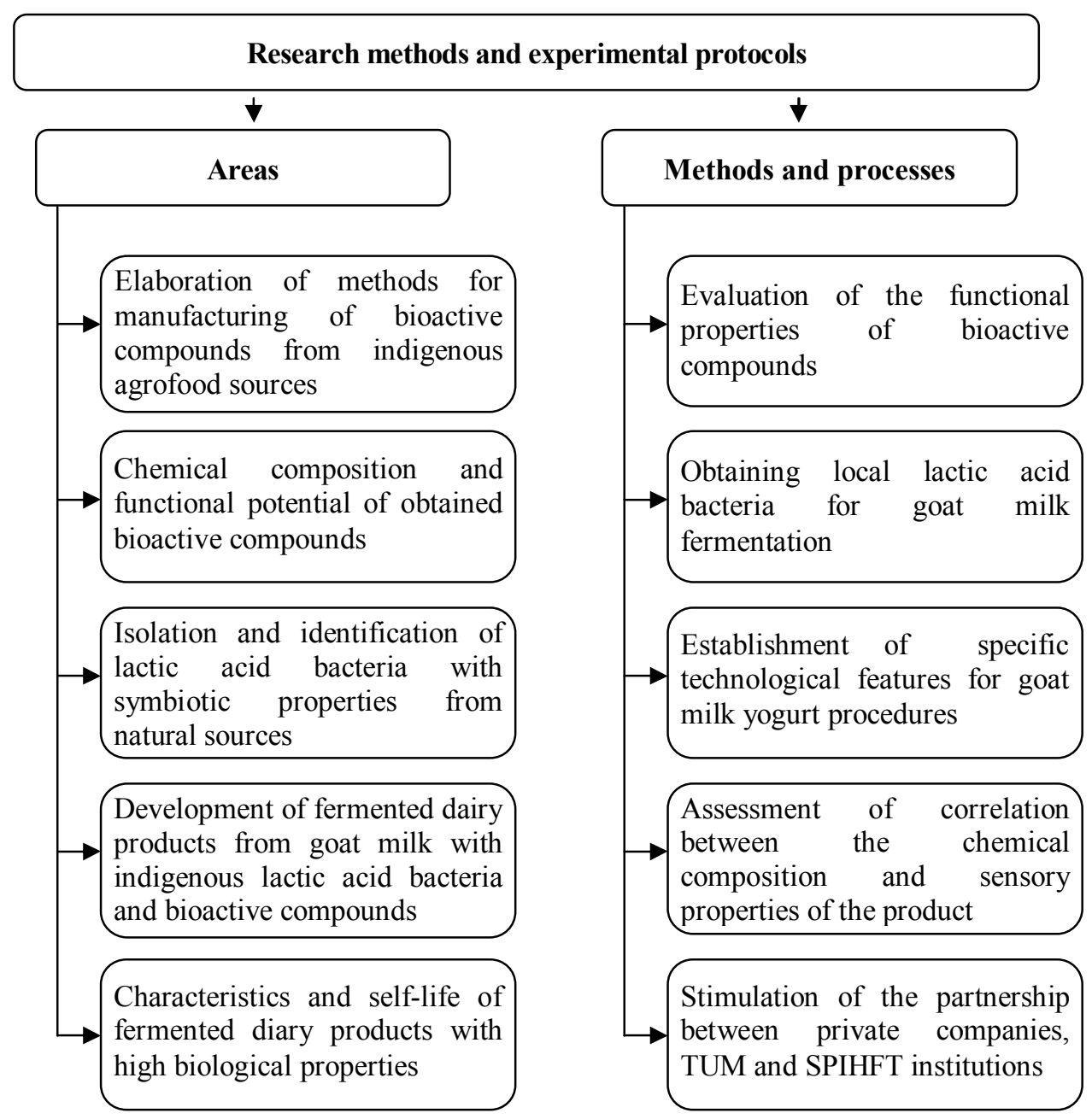

Figure 2. Research areas, methods and processes of InoBioProd

\section{Expected scientific results}

InoBioProd Project contribues to the development of investigations in the field of food biotechnology, engineering technology, food chemistry and microbiology, offering a high potential for application:

- Innovative technology for manufacturing of obtained bioactive compounds from local sources;

- General characteristic of functional potential of bioactive compounds;

- Scientifically justified process for producing of goat milk yogurt with high biological properties; 
- Sensorial, physico-chemical, structural and microbiological properties of developed yogurt;

- Technical regulations for goat milk yogurt.

However, manufacturing technology of goat milk yogurt by using original physical and chemical methods is a perspective direction that has a real potential for patenting. Unordinary solutions for resolving actual problems are expected. Real objects for patent present know-how, intellectual property of authors. It is obvious that the degree of patent and intellectual capacities depend on the level of special knowledge and fundamentals of young researchers, the ability of creative thinking, problem solving skills in biotechnology, engineering and microbiological analysis. Predicting the level prior patent is planned based on the preliminary results of the team, the dynamics of obtaining these results, the number of patents remain in force, whose authors are members of the team, the number of patents can be estimated:

- Patents regarding to processing technologies of raw materials 1-2 patents;

- Patents regarding to elaboration of food products 1-2 patents.

We note that this "account" number of patents do not appreciate their quality parameter, which we consider basic to any business, especially the scientific research.

\section{Benefits of InoBioProd}

The Project contributes to the diversification of food technology through valorisation of emerging technologies to meet the demands of consumers. The Project induces increased use of existing infrastructure, improves documentation and scientific information on basic and applied research in the field of food quality and safety, helps to explore human, research and development resources. The most valuable results are planned to be implemented partially at specialized university courses. Benefits of the InoBioProd Project have several areas (Figure 3).

The InoBioProd Project contribute significantly in the training of young researchers through obtaining team building skills for planning and conducting scientific researches, accumulation of new knowledge, obtaining and dissemination of scientific results. To increase participation and capacity of team building of young researchers in the Project are intended to finish $\mathrm{PhD}$ thesis of team members.

Realization and defending of $\mathrm{PhD}$ thesis in the frame of InoBioProd Project will increase the number of young researchers with scientific grade and respectively national competitiveness of internationalization and participation in different international programs, including the Framework Programme H2020. 


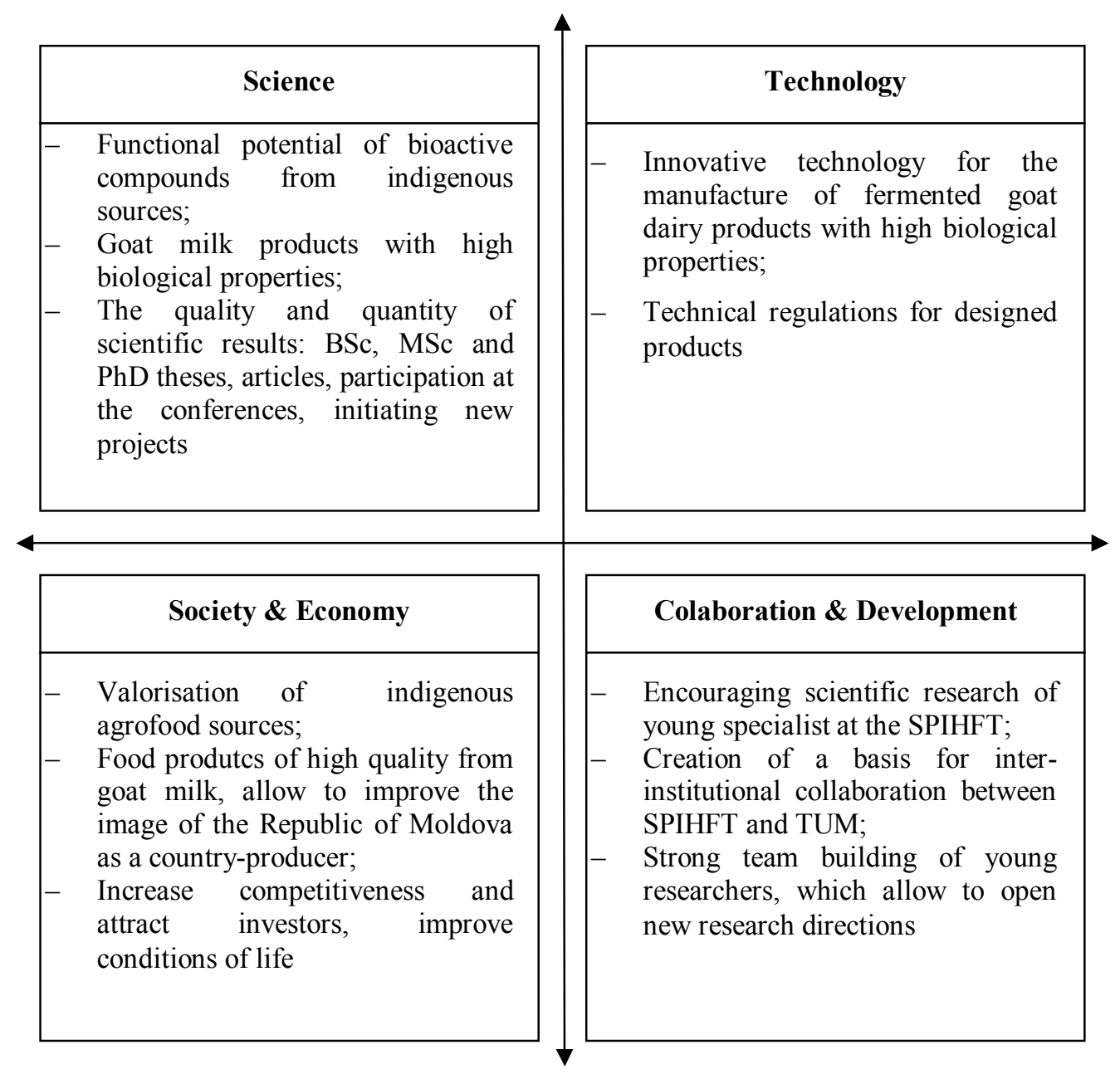

Figure 3. The Benefits of InoBioProd

\section{Application of InoBioProd}

Considering the importance of fermented dairy products from goat milk, which are in demand on internal and external markets, elaboration of the technological process for manufacturing of the products is necessary. Developed processes for the production of yogurt from goat milk with high biological properties will be approved in the Laboratory of Food Biotechnology of Scientific and Practical Institute of Horticulture and Food Technology and Scientific Centre for Training and Technology Transfer in Food Industry of TUM in the frame of "Etalon" enterprise. Application of the results on a large scale will be possible in case of producers motivation for investment in manufacturing new developed products, because all economic units, dealing with dairy production in the Republic of Moldova are private. 
At the first stage of research results implementation, potential beneficiaries are small private enterprises (II and SRL) from the filed of dairy technology. Furthermore, the volume of internal production of goat milk allows loading of enterprises of SA "JLC" type with high volumes of work.

Application of InoBioProd Project results in research and education is a step of major importance. The results will be included in the cycle of lectures, seminars and laboratory works for training in higher education, first and second cycle disciplines: Dairy Technology, Food Biotechnology, Food Chemistry, Physical Chemistry (Figure 4).

\section{Fields of application of the InoBioProd}

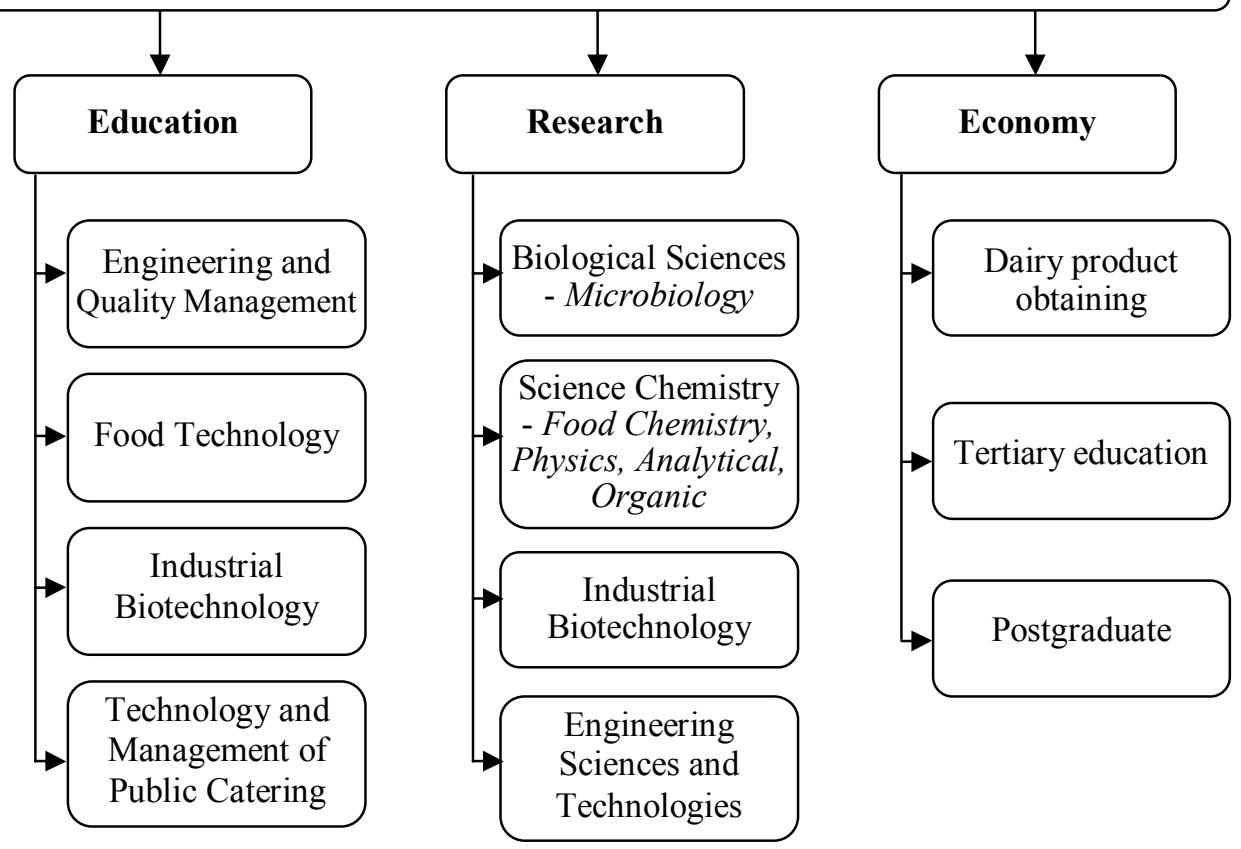

Figure 4. Application of InoBioProd

\section{Perspectives and further research}

Effective methods for bioactive compounds obtaining, identifying indigenous lactic acid bacteria, developement of yogurt with high biological properties and analysis of scientific results contribue to training and development of young researchers in the field.

During the Project work there is build a team of young researchers with high-potential, their results create perspectives for further research in the frame of the European Partnership for innovation and technology, increase competitiveness through creation of opportunities for new consortia (units, scientific researchers - businesses) to develop new 
improved technologies to increase the added value of technology at enterprises. In addition, this create opportunities for international collaboration through achieving top results, with prospects for marketing of new products.

The Project contributes to the diversification of food technology through valorisation of emerging technologies to meet the demands of consumers. The Project induces increased use of existing infrastructure, improves documentation and scientific information on basic and applied research in the field of food quality and safety, helps to explore human, research and development resources. The most valuable results will be implemented at specialized university courses.

\title{
Conclusions
}

Consumer interest for potential health benefits of a proper alimentation has led to a growing importance of the relationship between diet, specific food ingredients and health. Through the InoBioProd, it facilitates the development of science to solve some problems in this field, ensures increased research capabilities, innovation and dissemination of obtained scientific results and strengthens scientific cooperation of young researchers of R\&D and higher education institutions of the Republic of Moldova.

InoBioProd is planning to elaborate methods and recommendations on technological regimes for manufacturing of bioactive compounds from agrofood sources; technological scheme for obtaining of bioactive compounds; evaluate characteristics of nutritional, antioxidant and antimicrobial potential of samples of bioactive compounds and propose procedures and recipes justified scientifically regarding the manufacturing of yogurt with high biological properties according to the international regulations on food processing.

\begin{abstract}
Acknowledgments
This work was done in the framework of Independent Project for Young Researchers 16.80012.51.23A "Innovative product from goat milk with high biological properties" (InoBioProd), cofounded by the Ministry of Agriculture and Food Industry and coordinated by the Academy of Science of Moldova.
\end{abstract}

\section{References}

1. Abou Ayana I.A.A., Gamal El Deen A.A. (2011), Improvement of the properties of goat's milk Labneh using some aromatic and vegetable oils, International Journal of Dairy Science, 6(2), pp. 112-123.

2. Asresie A., Adugna M. (2014), Bioactive Properties of Goat Milk: It's Hypoallergenic, Nutritional and Therapeutic Significance: A Review, Global Journal of Animal Scientific Research, 2(4), pp. 315-320.

3. Aswal PP., Shukla A., Priyadarshi S. (2012), Yoghurt: Preparation, characteristics and recent advancements, Cibtech Journal of Bio-Protocols, 1(2), pp. 32-44.

4. Beshkova D.M., Simova E.D., Dimitrov Zh.PP., Simov Zh.I. (2011), Enhancing Proteolytic Activity, Nutritional and physiological benefits of caprine yogurt, Proceedings of IDF International Symposium on Sheep, Goat and other non-Cow Milk, Athens, pp. 154-156. 
5. Boycheva S., Dimitrov T., Naydenova N., Mihaylova G. (2011), Quality characteristics of yogurt from goat's milk, supplemented with fruit juice, Czech Journal of Food Science, 29(1), pp. 24-30.

6. Caleja C., Barros L., Antonio A.L., Carocho M., Oliveira M.B.PP.PP., Ferreira I.C.F.R. (2016), Fortification of yogurts with different antioxidant preservatives: A comparative study between natural and synthetic additives, Food Chemistry, 210, pp. 262-268.

7. Domagała J. (2008), Sensory evaluation and rheological properties of yogurts prepared from goat, cow and sheep milk, Electronic Journal of Polish Agricultural Universities, 11(3), pp. 1-8.

8. Damunupola D.A.PP.R., Weerathilake W.A.D.V., Sumanasekara G.S. (2014), Evaluation of quality characteristics of goat milk yogurt incorporated with beetroot juice, International Journal of Scientific and Research Publications, 4(10), pp. 1-5.

9. Gaddour A., Najari S., Aroum S., Abdennebi M. (2013), Local goat milk valorization and dairy products characterization in the southern Tunisia arid zone, International Journal of Current Microbiology and Applied Sciences, 2(6), pp. 318-323.

10. García V., Rovira S., Boutoial K., López M.B. (2014), Improvements in goat milk quality: A review, Small Ruminant Research, 121(1), pp. 51-57.

11. Hassan F.A.M., Abbas H.M., Abd El-Gawad M.A.M., Enab A.K. (2014), Goats dairy products as a potentially functional food, Life Science Journal, 11(9s), pp. 648-657.

12. (2016), Independent Project Proposal for Young Researchers "Innovative product from goat milk with high biological properties" (InoBioProd), , Chisinau.

13. Innocente N., Biasutti M., Rita F., Brichese R., Comi G., Iacumin L. (2016), Effect of indigenous Lactobacillus rhamnosus isolated from bovine milk on microbiological characteristics and aromatic profile of traditional yogurt, LWT - Food Science and Technology, 66, pp. 158-164.

14. Martinez J.L. (2007), Supercritical fluid extraction of nutraceuticals and bioactive compounds, CRC Press, USA, pp. 402.

15. Paz N.F., Oliveira E.G., Kairuz M.S.N., Ramón A.N. (2014), Characterization of goat milk and potentially symbiotic non-fat yogurt, Food Science and Technology (Campinas), 34(3), pp. 629-635.

16. Popovici C., Cartasev A., Caragia V., Migalatiev O., Coev Gh., Bogdan N., Grumeza I., Golubi R. (2017), InoBioProd Project Sustainability Strategies, Book of abstracts of the 83 International scientific conference of young scientist and students "Youth scientific achievements to the $21^{\text {st }}$ century nutrition problem solution", Part I, pp. 338.

17. Popovici C., Cartasev A., Caragia V., Migalatiev O., Coev Gh., Bogdan N., Grumeza I., Necrilova L., Golubi R. (2016), Innovative product from goat milk with high biological properties. Proceedings of the $5^{\text {th }}$ International Specialized Scientific and Practical Conference "Resource and Energy Saving Technologies of Production and Packing of Food Products as the Main Fundamentals of Their Competitiveness", p. 107.

18. Popovici C., Caragia V., Gaceu L., Cartasev A., Migalatiev O., Bogdan N., Grumeza I., Golubi R. (2017), Improvement of the properties of goat milk yogurt using berry juice, Book of abstracts of the $8^{\text {th }}$ International Symposium "Euroaliment - Mutatis mutandis in food" (accepted for publication).

19. Popovici C., Migalatiev O., Golubi R., Caragia V., Cartasev A., Coev Gh., Bogdan N., Grumeza I. (2017), Smart valorisation of industrial tomatoes by-products, Book of abstracts of the $4^{\text {th }}$ North and East European Congress on Food (NEEFood) "Global 
and Local Challenges in Food Science and Technology", Kaunas University of Technology, Lithuania (accepted for publication).

20. Ribeiro A.C., Ribeiro S.D.A. (2010), Specialty products made from goat milk, Small Ruminant Research, 89, pp. 225-233.

21. Saha B.N.PP., Vasiljevica T., McKechnieb S., Donkor O.N. (2016), Physicochemical, textural and rheological properties of probiotic yogurt fortified with fibre-rich pineapple peel powder during refrigerated storage, LWT - Food Science and Technology, 65, pp. 978-986.

22. Samson A., Ammar O., Kebbe B.O., Imad T. (2014), The characterization of the physicochemical and sensory properties of full-fat, reduced-fat and low-fat bovine, caprine, and ovine Greek yogurt (Labneh), Food Science and Nutrition, 2(2), pp. 164173.

23. Serhan M., Mattar J., Debs L. (2016), Concentrated yogurt (Labneh) made of a mixture of goats' and cows' milk: Physicochemical, microbiological and sensory analysis, Small Ruminant Research, 138, pp. 46-52.

24. Shori A.B., Baba A.S. (2015), Survival of Bifidobacterium bifidum in cow- and camelmilk yogurts enriched with Cinnamomum verum and Allium sativum, Journal of the Association of Arab Universities for Basic and Applied Sciences, 18, pp. 7-11.

25. Yangilar F. (2013), As a Potentially Functional Food: Goats' Milk and Products, Journal of Food and Nutrition Research, 1 (4), pp. 68-81. 